\title{
Observations of filamentary structures near the vortex edge in the Arctic winter lower stratosphere
}

\author{
C. Kalicinsky ${ }^{1}$, J.-U. Grooß ${ }^{2}$, G. Günther ${ }^{2}$, J. Ungermann ${ }^{2}$, J. Blank ${ }^{2}$, S. Höfer ${ }^{2}$, L. Hoffmann ${ }^{3}$, P. Knieling ${ }^{1}$, \\ F. Olschewski ${ }^{1}$, R. Spang ${ }^{2}$, F. Stroh ${ }^{2}$, and M. Riese ${ }^{2}$ \\ ${ }^{1}$ Department of Physics, University of Wuppertal, Wuppertal, Germany \\ ${ }^{2}$ Institute of Energy and Climate Research - Stratosphere (IEK-7), Research Centre Jülich GmbH, Jülich, Germany \\ ${ }^{3}$ Jülich Supercomputing Centre, Research Centre Jülich GmbH, Jülich, Germany
}

Correspondence to: C. Kalicinsky (kalicins@uni-wuppertal.de)

Received: 6 March 2013 - Published in Atmos. Chem. Phys. Discuss.: 19 April 2013

Revised: 13 August 2013 - Accepted: 11 September 2013 - Published: 7 November 2013

\begin{abstract}
The CRISTA-NF (Cryogenic Infrared Spectrometers and Telescope for the Atmosphere - New Frontiers) instrument is an airborne infrared limb sounder operated aboard the Russian research aircraft M55-Geophysica. The instrument successfully participated in a large Arctic aircraft campaign within the RECONCILE (Reconciliation of essential process parameters for an enhanced predictability of Arctic stratospheric ozone loss and its climate interactions) project in Kiruna (Sweden) from January to March 2010.

This paper concentrates on the measurements taken during one flight of the campaign, which took place on 2 March in the vicinity of the polar vortex. We present two-dimensional cross-sections of derived volume mixing ratios for the trace gases $\mathrm{CFC}-11, \mathrm{O}_{3}$, and $\mathrm{ClONO}_{2}$ with an unprecedented vertical resolution of about 500 to $600 \mathrm{~m}$ for a large part of the observed altitude range $(\approx 6-19 \mathrm{~km})$ and a dense horizontal sampling along flight direction of $\approx 15 \mathrm{~km}$. The trace gas distributions show several structures, for example a part of the polar vortex and a vortex filament, which can be identified by means of $\mathrm{O}_{3}-\mathrm{CFC}-11$ tracer-tracer correlations.

The observations made during this flight are interpreted using the chemistry and transport model CLaMS (Chemical Lagrangian Model of the Stratosphere). Comparisons of the observations with the model results are used to assess the performance of the model with respect to advection, mixing, and the chemistry in the polar vortex. These comparisons confirm the capability of CLaMS to reproduce even very small-scale structures in the atmosphere, which partly have a vertical extent of only $1 \mathrm{~km}$. Based on the good agreement between simulation and observation, we use artificial (passive) trac-
\end{abstract}

ers, which represent different air mass origins (e.g. vortex, tropics), to further analyse the CRISTA-NF observations in terms of the composition of air mass origins. These passive tracers clearly illustrate the observation of filamentary structures that include tropical air masses. A characteristic of the Arctic winter 2009/10 was a sudden stratospheric warming in December that led to a split of the polar vortex. The vortex re-established at the end of December. Our passive tracer simulations suggest that large parts of the re-established vortex consisted to about $45 \%$ of high- and mid-latitude air.

\section{Introduction}

The upper troposphere/lower stratosphere (UTLS) region plays an important role in the climate system (e.g. IPCC, 2007; Riese et al., 2012). Changes in the chemical composition of this region result in particularly large changes in radiative forcing of the atmosphere. Therefore, quantifying the chemical composition of this region and the underlying processes represents a crucial task. During winter and spring, the composition of the lower Arctic stratosphere is strongly influenced by mixing of polar and mid-latitude air masses, a process that is associated with the occurrence of fine structures and filaments in trace gas distributions. These structures can be considered as part of a scale cascade from synoptic-scale tongue-like structures (streamers) over elongated filaments down to small-scale three-dimensional turbulence. Different types of observations are necessary to detect and analyse these structures. Synoptic-scale streamers were 
observed and analysed by several satellite limb sounders, e.g. the Cryogenic Infrared Spectrometers and Telescopes for the Atmosphere (CRISTA) instrument (e.g. Riese et al., 1999, 2002), whereas in situ observations from high-flying research aircraft provided a wealth of information on small-scale mixing processes (e.g. Hoor et al., 2002; Konopka et al., 2004). The airborne Cryogenic Infrared Spectrometers and Telescope for the Atmosphere - New Frontiers (CRISTA-NF) instrument is well suited to fill the gap between global satellite observations and airborne in situ measurements in terms of spatial resolution and coverage, since its observations offer a better vertical resolution than satellite observations and an enhanced coverage compared to in situ measurements.

CRISTA-NF is an infrared limb sounder, which utilises the centre telescope and spectrometer gratings of the satellite instrument CRISTA (e.g. Offermann et al., 1999; Grossmann et al., 2002). The instrument measures thermal emissions of trace gases (4 to $15 \mu \mathrm{m}$ ) with a high vertical sampling $(\approx 250 \mathrm{~m})$ and dense horizontal sampling along flight track $(\approx 15 \mathrm{~km})$. The employed retrieval scheme allows for deriving profiles of selected trace gases with a very high vertical resolution (up to about $400 \mathrm{~m}$; Ungermann et al., 2012). CRISTA-NF is operated aboard the high-flying Russian research aircraft M55-Geophysica which offers a maximum flight altitude of about $20 \mathrm{~km}$ and, therefore, is an ideal platform for limb measurements of UTLS composition. The instrument was successfully employed onboard M55Geophysica during the tropical aircraft campaigns SCOUTO3 (e.g. Hoffmann et al., 2009; Spang et al., 2008) and AMMA-SCOUT-O3 (e.g. Weigel et al., 2012).

In this paper, we discuss observations of polar vortex air masses and fine filamentary structures based on twodimensional distributions of the trace gases CFC- $11, \mathrm{O}_{3}$, and $\mathrm{ClONO}_{2}$ with unprecedented vertical resolution for atmospheric limb sounding (Ungermann et al., 2012). The observations were made during a M55-Geophysica flight from Spitsbergen to Kiruna/Sweden on 2 March 2010 in the framework of the European RECONCILE (Reconciliation of essential process parameters for an enhanced predictability of Arctic stratospheric ozone loss and its climate interactions; von Hobe et al., 2013) project. During this flight, M55Geophysica encountered an interesting meteorological situation, where a large number of small-scale structures (incl. pronounced filaments) were observed in the spatial distributions of CFC-11, ozone, chlorine nitrate, and other trace gases. We analyse these observations based on $\mathrm{O}_{3}-\mathrm{CFC}-11$ tracer-tracer correlations and simulations with the Chemical Lagrangian Model of the Stratosphere (CLaMS; e.g. McKenna et al., 2002a, b). CLaMS enables the use of artificial tracers (passive tracers) representing different air mass origins (e.g. vortex, tropics). These passive tracers are only advected and mixed and can be used to analyse the composition of origins of observed air masses (Günther et al., 2008).

The CRISTA-NF instrument is briefly introduced in Sect. 2. Section 3 gives an overview of the CLaMS simu- lations used for our analyses. The meteorological situation and the CRISTA-NF observations are described in Sects. 4 and 5. In Sect. 6, we show that the passive tracer concept of CLaMS provides further insight into the origin of the trace gas structures observed by CRISTA-NF. Furthermore, we use the passive tracer concept to assess the effects of a sudden stratospheric warming (SSW) that occurred in early December 2009 (associated with a vortex split) on the re-established polar vortex (end of December 2009). A short summary and some conclusions are given in Sect. 7.

\section{CRISTA-NF observations}

CRISTA-NF measures thermal emissions of several atmospheric trace gases (e.g. CFC-11, $\mathrm{O}_{3}, \mathrm{ClONO}_{2}, \mathrm{HNO}_{3}$ ) in the spectral range from 4 to $15 \mu \mathrm{m}$ and in the altitude range from flight altitude (up to $20 \mathrm{~km}$ ) down to $5 \mathrm{~km}$. Kullmann et al. (2004) give a detailed insight into the design of the cryostat and the optical system of CRISTA-NF. The calibration procedure and improvements concerning the data processing for the RECONCILE aircraft campaign are described by Schroeder et al. (2009) and Ungermann et al. (2012), respectively.

The viewing direction of the instrument is perpendicular to the flight direction to the right side of the aircraft. A Herschel telescope with a tiltable mirror scans the atmosphere with a vertical sampling of about $250 \mathrm{~m}$ from flight altitude down to $\approx 5 \mathrm{~km}$. The incoming radiance is spectrally dispersed by two Ebert-Fastie (e.g. Fastie, 1991) grating spectrometers with different spectral resolving powers of $\lambda / \Delta \lambda \sim 1000$ and 500 ( $\lambda$ denotes the wavelength and $\Delta \lambda$ denotes the distance between two spectral points, which can be resolved), respectively, and finally measured by semiconductor detectors ( $\mathrm{Si}: \mathrm{Ga}$ ) that are operated at temperatures of about $13 \mathrm{~K}$. These low temperatures allow for a measurement speed of $\approx 1.2 \mathrm{~s}$ per spectrum coupled with a good signal-to-noise ratio. A complete altitude scan consisting of 60 spectra can be performed within $\approx 70 \mathrm{~s}$. Based on the speed of the aircraft this fast measurement speed leads to a horizontal sampling along flight direction of about $15 \mathrm{~km}$.

The fine vertical and horizontal sampling combined with a comparably small vertical field of view (FOV) of 3 arc min $(\approx 300 \mathrm{~m}$ at $10 \mathrm{~km}$ tangent height, Spang et al., 2008) provides the basis for the retrieval of two-dimensional trace gas distributions with high spatial resolution (Ungermann et al., 2012).

We use a setup of 13 integrated micro windows (IMW) in the spectral range from 775 to $865 \mathrm{~cm}^{-1}$, which is covered by the CRISTA-NF low-resolution spectrometer detector channel number 6 (LRS 6), to obtain the retrieval results shown in Sect. 5 . The trace gas profiles are derived by means of the JUelich RApid Spectral SImulation Code version 2 (JURASSIC2; e.g. Ungermann et al., 2010, 2013), a further development of JURASSIC, which was successfully 
used to analyse measurements from various satellites and airborne limb-emission measurements (e.g. Hoffmann et al., 2008; Hoffmann and Alexander, 2009; Weigel et al., 2012). The main targets of the retrieval are CFC- $11, \mathrm{O}_{3}, \mathrm{ClONO}_{2}$, $\mathrm{HNO}_{3}, \mathrm{H}_{2} \mathrm{O}$, and $\mathrm{CCl}_{4}$. In addition, aerosol, temperature, PAN, CFC-113, and HCFC-22 are retrieved from the measurements as secondary targets. The list of the IMWs used and the corresponding retrieval targets is displayed in Table 1. A full error analysis is performed regarding all nonretrieved gases, instrument errors, forward model errors, spectroscopic line uncertainties and the smoothing error. The combined errors of trace gas volume mixing ratios for CFC11 are typically between 15 and $20 \mathrm{pptv}$ and the errors for $\mathrm{ClONO}_{2}$ and ozone on average about $15 \%$. Remarkable is the unprecedented vertical resolution of 400 to $500 \mathrm{~m}$ for CFC-11 in the altitude range from flight altitude down to approximately $12 \mathrm{~km}$. The vertical resolution in this altitude range is about 500 to $600 \mathrm{~m}$ and $500 \mathrm{~m}$ to $1 \mathrm{~km}$ for $\mathrm{O}_{3}$ and $\mathrm{ClONO}_{2}$, respectively. The retrieval technique and validation against measurements by other instruments is described in detail by Weigel et al. (2010) and Ungermann et al. (2012). The derivation of the trace gas cross-sections was since improved by means of cross-section retrievals to further reduce the effect of stochastic errors such as a remaining line-ofsight uncertainty (Ungermann, 2013).

\section{CLaMS simulations}

The model used in the following sections for comparison and further analyses is the Chemical Lagrangian Model of the Stratosphere (CLaMS). It was first developed as a twodimensional model on isentropic surfaces (McKenna et al., 2002b) and later on extended to three dimensions by application of cross-isentropic transport (Konopka et al., 2004). The introduction of the hybrid vertical coordinate $\zeta$ (equal to the potential temperature in the stratosphere and parallel to the pressure isolines in the troposphere) expanded the model to the tropopause region and the troposphere (Konopka et al., 2007).

CLaMS simulates an ensemble of air parcels moving along trajectories, which are calculated by means of meteorological wind fields. The grid in CLaMS is defined by the positions of these air parcels and, therefore, this grid is time-dependent and irregular. Each transport step consists of an advection step, in which the air parcels follow the trajectories, and a subsequent mixing step. The mixing step is realised utilising a dynamically adaptive grid. If the distance between an air parcel and one of its prior nearest neighbours falls below a critical distance after an advection step, the two air parcles are merged into one air parcel. If the distance exceeds a critical distance, a new air parcel is inserted in between the two former ones. The critical distances are defined by the Lyapunov exponent $\lambda_{c}$ and the characteristics of a new or a merged air parcel are the mean characteristics of the
Table 1. Integrated micro windows (IMW) as used in the retrieval and the corresponding main retrieval targets.

\begin{tabular}{lcc}
\hline IMW \# & spectral range $\left(\mathrm{cm}^{-1}\right)$ & main target \\
\hline 1 & $777.5-778.5$ & $\mathrm{O}_{3}$ \\
2 & $784.0-785.0$ & $\mathrm{H}_{2} \mathrm{O}$ \\
3 & $787.0-790.0$ & offset \\
4 & $791.5-793.0$ & temperature \\
5 & $794.1-795.0$ & PAN \\
6 & $795.5-796.5$ & $\mathrm{O}_{3}$ \\
7 & $796.6-797.5$ & $\mathrm{CCl}_{4}$ \\
8 & $808.0-809.0$ & $\mathrm{HCFC}-22$ \\
9 & $810.0-813.0$ & $\mathrm{ClONO}_{2}$ \\
10 & $820.5-821.5$ & $\mathrm{HCFC}-22$ \\
11 & $831.0-832.0$ & aerosol \\
12 & $846.0-847.0$ & $\mathrm{CFC}-11^{2}$ \\
13 & $863.0-866.0$ & $\mathrm{HNO}_{3}$ \\
\hline
\end{tabular}

two prior air parcels. The mixing strength is adjusted by the Lyapunov exponent $\lambda_{\mathrm{c}}$ (logarithmic expansion rate), where a smaller value induces more mixing and vice versa. By using this approach the grid is dynamically adapted after each advection step, which produces mixing and, additionally, leads to a quasi-uniformity of the grid (the mean distance of the air parcels remains within a small range). A detailed description of the dynamically adaptive grid is given by McKenna et al. (2002b) and Konopka et al. (2004).

The model includes 48 chemical species and 144 chemical reactions ( 84 binary, 13 ternary, 36 photolysis, 11 heterogeneous) as described by Grooß et al. (2013). The formation, sedimentation, and evaporation of NAT (nitric acid trihydrate) particles is realised by means of a Lagrangian sedimentation tool described by Grooß et al. (2005) to simulate de- and renitrification processes in the stratosphere.

The simulations were initialised on 1 December 2009. The atmospheric trace gases are partly initialised utilising globally distributed measurements by three satellite instruments (Microwave Limb Sounder aboard Aura satellite (Aura-MLS; Waters et al., 2006), Atmospheric Chemistry Experiment - Fourier Transform Spectrometer (ACE-FTS; Bernath et al., 2005) and Michelson Interferometer for Passive Atmospheric Sounding - ENVisat (MIPAS-ENV; Fischer et al., 2008)) and partly using correlations between trace gases or partitioning within chemical families.

A model concept utilising artificial (passive) tracers is used to analyse air masses in terms of their origin (see e.g. Günther et al., 2008). A whole set of these tracers, each of them representing a different air mass origin (tropics, midlatitudes, high latitudes, and vortex), is applied in the model. Hence, each air parcel includes four passive tracers describing the composition of origins. The passive tracers of an air parcel are initialised based on values of modified potential vorticity $(\mathrm{mPV})$ of this air parcel at the initialisation date. Modified potential vorticity is a scaled form of 
Table 2. Summary of the CLaMS setup.

\begin{tabular}{ll}
\hline horizontal resolution (mean distance of air parcels) & $70 \mathrm{~km}$ \\
horizontal range & $0-90^{\circ} \mathrm{N}$ \\
vertical levels & 50 \\
vertical resolution & $\approx 500 \mathrm{~m}$ (for $\zeta>380 \mathrm{~K})$ \\
vertical range & $300 \mathrm{~K}<\zeta<900 \mathrm{~K}$ \\
meteorological wind fields & ECMWF ERA interim data $\left(1^{\circ} \times 1^{\circ}\right)$ \\
heating/cooling rates & ECMWF clear sky radiative heating rate \\
time step $\Delta t$ & $24 \mathrm{~h}$ \\
Lyapunov exponent $\lambda_{\mathrm{c}}$ & $1.5 \mathrm{~d}^{-1}$ \\
NAT nucleation rate & $8 \times 10^{-5} \mathrm{~cm}^{-1} \mathrm{~h}^{-1}$ \\
& $(10$ times larger than in Grooß et al., 2005)
\end{tabular}

Table 3. Summary of the modified potential vorticity boundaries for the artificial tracers and the corresponding air mass origin.

\begin{tabular}{ll}
\hline mPV boundary (in PVU) & air mass origin \\
\hline $0-8$ & low latitudes \\
$8-14.7$ & mid-latitudes \\
$14.7-19.8$ & high latitudes \\
$>19.8$ & vortex \\
\hline
\end{tabular}

potential vorticity $(\mathrm{PV})$ to reduce the altitude dependence of PV, which is increasing with increasing altitude. Details about the description and derivation of $\mathrm{mPV}$ are given by Lait (1994) and Müller and Günther (2003). Table 3 summarises the $\mathrm{mPV}$ boundary conditions for each passive tracer. The boundaries are chosen because they roughly coincide with the boundaries between the different types of air. For example, the boundary value of 19.8 potential vorticity units (PVU; $10^{-6} \mathrm{~K} \mathrm{~m}^{2}\left(\mathrm{~kg} \mathrm{~s}^{-1}\right.$ ) agrees very well with the vortex edge defined by the criterion after Nash et al. (1996). In the context of this paper, the air mass origin high latitudes denotes air masses in the transition region between the vortex edge and the mid-latitudes. If an air parcel fulfils one of the given conditions, the corresponding passive tracer is set to 1 and all other tracers to zero. In the model simulation these tracers are only advected and mixed. Thus, the sum of all tracers in one air parcel is always 1 and the value of each single passive tracer gives the proportion of the corresponding air mass origin, whereby 1 denotes $100 \%$. The composition of an air parcel in terms of the passive tracers therefore reflects the composition of the air masses in terms of their origin and can be used to analyse mixing processes and to identify different air masses. We use two different initialisation dates for the passive tracers. For the first simulation the passive tracers are initialised on 1 December 2009 (identical to initialisation date of the trace gases and starting point of simulation). For the second simulation the passive tracers are initialised on 15 January 2010 to analyse the evolution of the vortex during the aircraft campaign (17 January to 10 March 2010). In the latter case, except that the passive tracers are initialised on 15 January, everything else is identical to the simulation described above.

\section{Flight path and meteorological situation}

During the RECONCILE aircraft campaign 12 flights took place in the time period from 17 January to 10 March 2010. The flight (flight 11 of the campaign) discussed in this paper took place on 2 March 2010. This flight is chosen because of the favourable measurement conditions during the flight (few aircraft manoeuvres, cloud-free) and the interesting dynamical situation. The polar vortex was very variable and unstable during the winter 2009/10. It split twice during two sudden stratospheric warmings. The first split occurred in December and the vortex re-established again at the end of December. During this split event some mid-latitude air masses were included in the vortex. The second split took place in February and the two parts of the vortex rejoined in early March. The presence of polar stratospheric clouds together with very cold temperatures occurred in January, which led to chlorine activation. Ozone depletion inside the vortex started after the sunlight returned. A discussion about the evolution of the vortex is given e.g. by Dörnbrack et al. (2012) and von Hobe et al. (2013). Thus, the analysed flight took place during the time period when the vortex rejoined again.

Figure 1 displays the flight path of the M55-Geophysica during this flight as a black line. The flight started at the airport of Longyearbyen on Spitsbergen heading towards northeast. After a turn at roughly $82^{\circ} \mathrm{N}$ the aircraft flew towards south and landed at the airport of Kiruna (Sweden). The highest altitudes reached by the aircraft were approximately $19 \mathrm{~km}$ at the end of the flight.

The other quantity depicted in the two plots is the so-called cloud index (CI). The CI is the ratio (IMW1/IMW2) between the spectrally integrated radiance in two specific integrated micro windows. While the IMW1 in the range from 791 to $793 \mathrm{~cm}^{-1}$ is mostly dominated by thermal emissions of $\mathrm{CO}_{2}$, the IMW2 $\left(832-834 \mathrm{~cm}^{-1}\right)$ is located in an atmospheric window region and, therefore, dominated by aerosol (e.g. Spang et al., 2008). A low CI value indicates the presence of clouds 


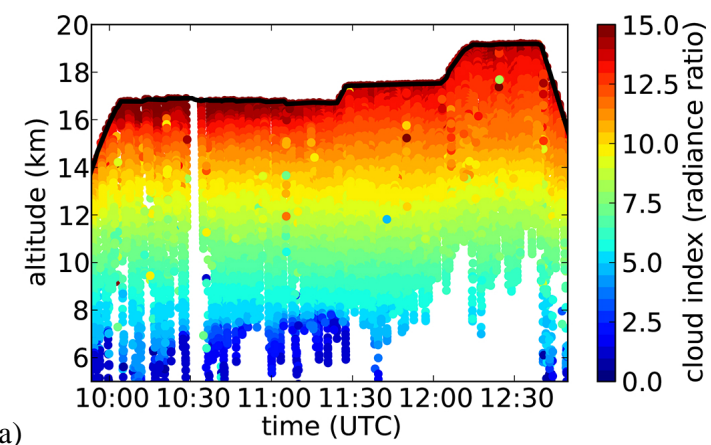

(a)

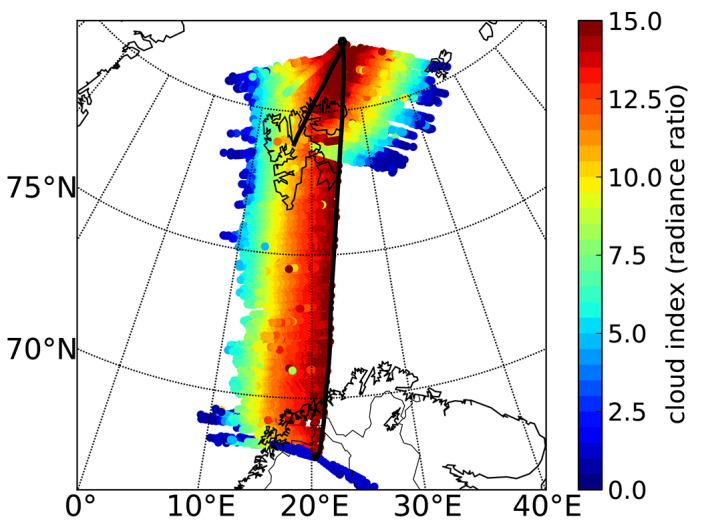

Fig. 1. CRISTA-NF cloud index for RECONCILE flight 11 (2 March 2010) as cross-section plot (a) and in longitude-latitude domain (b). The solid black line shows the observer altitude in the cross-section plot and the observer location in the longitude-latitude plot. The turn of the aircraft is indicated by the white vertical stripe in the cross-section plot due to the lack of measurements during the turn.

or optically thick conditions, whereas a high CI value shows cloud-free measurements and for that reason optimal conditions in terms of trace gas retrievals. The $\mathrm{CI}$ is plotted at the tangent points of the CRISTA-NF measurements. The tangent point denotes the closest point of the LOS (line of sight) to Earth. Under cloud-free conditions, the CI typically decreases with decreasing altitude because of the increasing aerosol and water vapour continuum (see Spang et al., 2008). During this flight the typical decrease is observed down to a certain altitude. But in many profiles the CI values then fall down from 4 to 1 within about $500 \mathrm{~m}$ height difference. This steep decrease cannot be explained by the increasing water vapour continuum alone. The presence of optically very thick conditions due to clouds (or a thick aerosol layer) is necessary. Assuming a CI value of 3.5 as a conservative threshold value to define this transition region, cloud-free conditions are present down to approximately $8 \mathrm{~km}$ during the flight. Below $8 \mathrm{~km}$ tropospheric clouds are visible indicated by a very low CI value (about 1 ) and dark blue colours.

The vertical and horizontal distribution of the measurements clearly shows that the horizontal distance between a tangent point and the instrument is increasing with de-

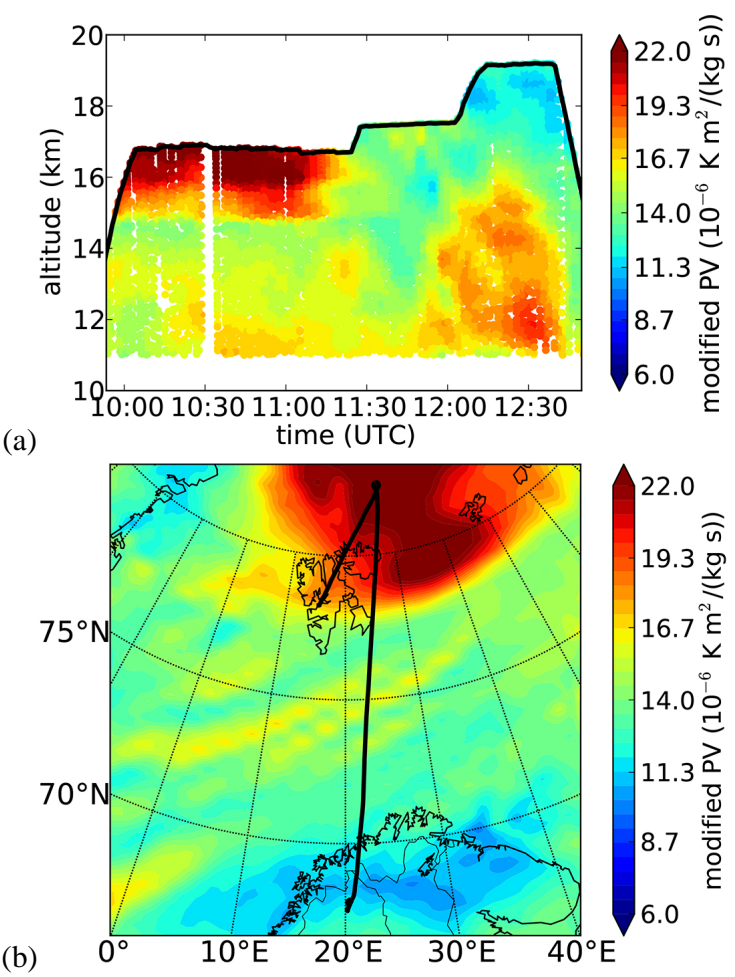

Fig. 2. Modified potential vorticity (mPV) derived from ECMWF operational analysis data for RECONCILE flight 11 (2 March 2010). Panel (a) shows $\mathrm{mPV}$ at the tangent points of the CRISTANF measurements and panel (b) shows the horizontal distribution of $\mathrm{mPV}$ at $81 \mathrm{mbar}$ at 12:00 UTC. For details see caption of Fig. 1.

creasing tangent height. Hence, the two-dimensional crosssections of trace gas volume mixing ratios shown in the following sections are rather slant.

The meteorological situation in the vicinity of the polar vortex is analysed using mPV (introduced in Sect. 3). ECMWF (European Centre for Medium-Range Weather Forecasts) operational analysis data with a longitude and latitude grid spacing of $0.5^{\circ}$ are used to calculate mPV. Figure $2 \mathrm{a}$ shows $\mathrm{mPV}$ at the tangent points of the CRISTA-NF measurements and Fig. $2 \mathrm{~b}$ shows $\mathrm{mPV}$ at the pressure level of $81 \mathrm{mbar}$ at 12:00 UTC. This pressure level corresponds to the flight altitude of about $17 \mathrm{~km}$ at the beginning of the flight. Müller and Günther (2003) showed that modified PV is a very useful and valid quantity to study air masses in the vicinity of the polar vortex down to a potential temperature of about $350 \mathrm{~K}$. In the altitude region between the tropopause and a few kilometres above, enhanced values of mPV occur. This behaviour is similar to what is observed for the squared Brunt-Väisälä frequency (see e.g. Birner et al., 2006). Thus, the enhanced $\mathrm{mPV}$ values are a sign of the tropopause and have to be excluded from the analysis. Fig. 2a shows mPV only in the altitude range from flight altitude down to $11 \mathrm{~km}$.

A part of the polar vortex is clearly visible at the beginning of the flight and northeast of Longyearbyen, indicated 
by high mPV values (larger than 20 PVU; compare Table 3). The vertical extent of this area with high $\mathrm{mPV}$ goes from flight altitude down to about $15 \mathrm{~km}$. Thus, the first part of the flight took place inside the polar vortex and the aircraft left it at about 11:15 UTC. The edge of the vortex is indicated by the steep gradient in mPV. Additionally, a second prominent structure showing high $\mathrm{mPV}$ values is visible at the end of the flight below $16 \mathrm{~km}$ (see Fig. 2a). The mPV values in this structure are in the range of 16 to $20 \mathrm{PVU}$. These high values most likely indicate air masses with a high fraction of air originating from the polar vortex. Apart from these two areas with high $\mathrm{mPV}$ values, an area showing $\mathrm{mPV}$ values below 12 PVU is visible immediately below flight altitude at the end of the flight (see Fig. 2a). The air masses in this area are therefore most likely of mid- or low-latitude origin.

In summary, the cross-section of modified PV shows three distinct areas: a part of the polar vortex, a structure with a high fraction of vortex air masses and an area containing air masses probably originating from mid- or low latitudes.

\section{CRISTA-NF retrieval results}

In this section we present the trace gas distributions of CFC$11, \mathrm{O}_{3}$, and $\mathrm{ClONO}_{2}$ derived from CRISTA-NF measurements. Furthermore, the origin of air masses in different observed structures is analysed using $\mathrm{O}_{3}-\mathrm{CFC}-11$ tracer-tracer correlations.

Figure 3 displays the cross-sections of CFC-11, $\mathrm{ClONO}_{2}$, and ozone for flight 11 (2 March 2010). The first trace gas CFC-11 is chemically inert and has a stratospheric lifetime of about $45 \mathrm{yr}$ (WMO, 2007). Thus, it is well suited to analyse dynamical processes in the lower stratosphere. Ozone and $\mathrm{ClONO}_{2}$ are mainly involved in the ozone chemistry inside the polar vortex in winter and spring. All retrieval results are displayed between flight altitude and $10 \mathrm{~km}$ to focus on the relevant altitude range. The retrieved volume mixing ratios (VMRs) above flight altitude are statistically insignificant and therefore omitted. Additionally, all results showing a measurement contribution of less than 0.7 are excluded. A measurement contribution of 1 means that the result is only determined by measurements, whereas a measurement contribution of zero implies that the result is only influenced by the a priori state. The retrieval results for CFC-11 and ozone (Fig. 3a and c) show a measurement contribution above 0.7 (typically close to 1 ) and, therefore, the volume mixing ratios are of high quality. In the case of $\mathrm{ClONO}_{2}$ the measurement contribution partly drops below 0.7 at the beginning of the flight.

The distribution of CFC-11 (Fig. 3a) shows three prominent structures with low VMRs. The first one is visible from the beginning of the flight until 11:15 UTC in the altitude range from flight altitude down to approximately $16 \mathrm{~km}$. The CFC-11 VMRs in this region partly drop below 20 pptv. Thus, the relative error increases because of these very low

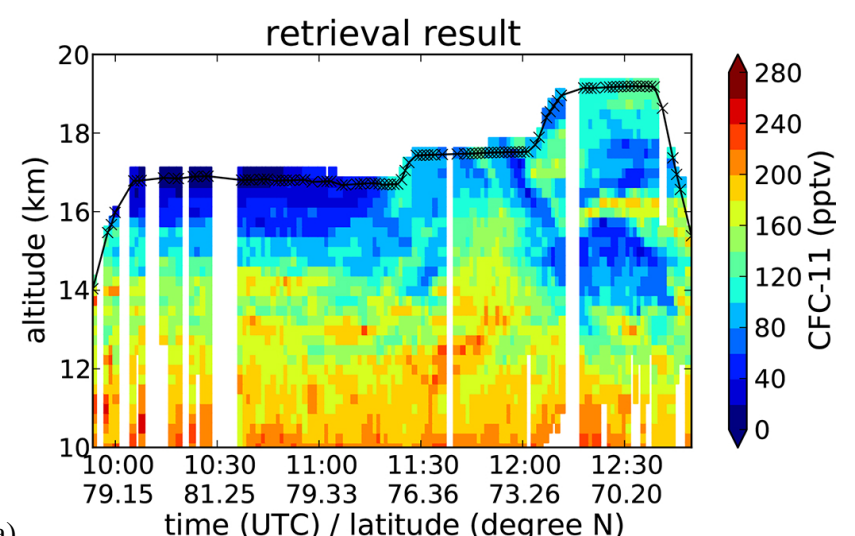

(a)

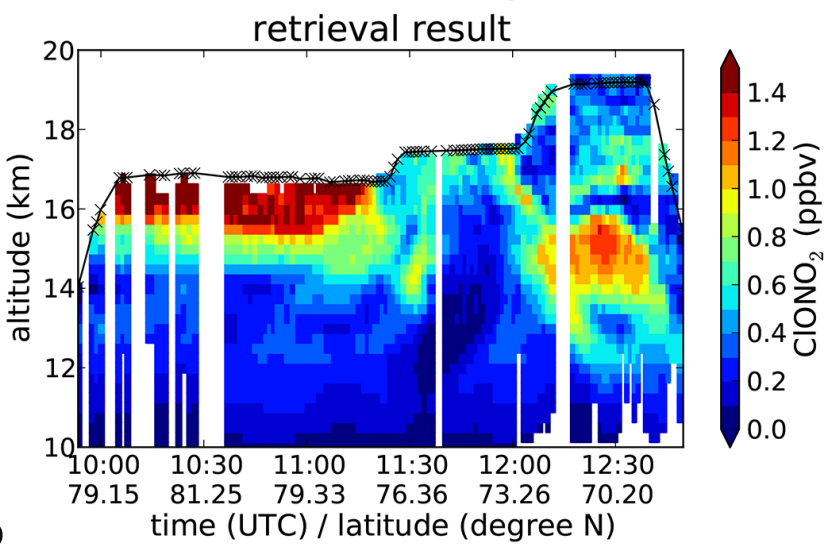

(b)

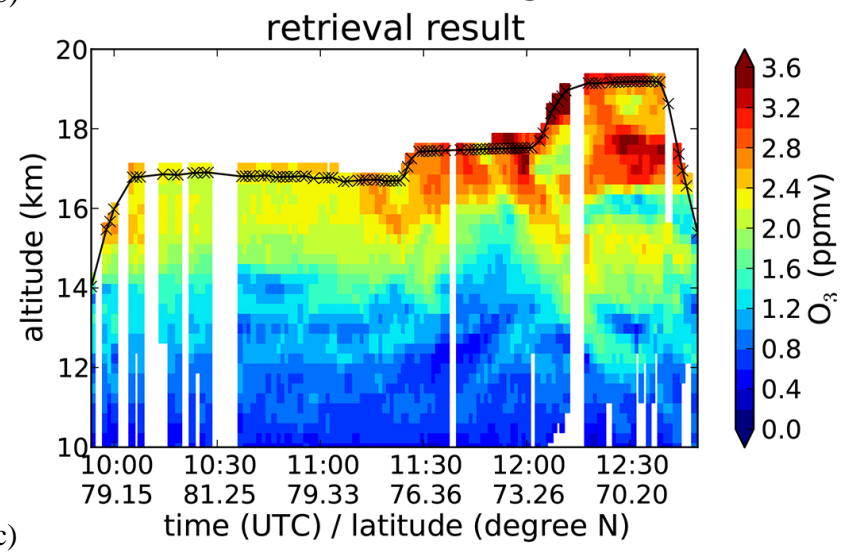

Fig. 3. CRISTA-NF retrieval results for CFC-11, $\mathrm{ClONO}_{2}$, and $\mathrm{O}_{3}$ for RECONCILE flight 11 (2 March 2010). All results with a measurement contribution of less than 0.7 are excluded. The solid black line shows the observer altitude and the position (time) of each profile is marked by a black cross. Additionally, the abscissa displays the latitude at $12 \mathrm{~km}$ tangent height. The vertical white stripes show times with insufficient measurements by CRISTA-NF due to strong aircraft movements (e.g. turn at about 10:30 UTC).

VMRs and reaches values up to $100 \%$. But nevertheless, comparisons with in situ measurements presented by Ungermann et al. (2012) show that the derived values are reliable. The very low CFC-11 VMRs and the simultaneously high $\mathrm{mPV}$ values are a reliable indicator for vortex air. The 
steep gradient in the CFC-11 VMRs at the vortex edge (about 11:15 UTC) confirms that the edge acts as an effective mixing barrier. The gradient is largest at the highest altitude (flight altitude), where an increase of the CFC-11 VMRs by about 70 pptv within a few kilometres is observed (compare Ungermann et al., 2012), and gets smaller with decreasing altitude. Thus, the mixing barrier weakens with decreasing altitude until it vanishes. Figure 3a shows two other structures with low CFC-11 VMRs at the end of the flight. One is located at altitudes below $16 \mathrm{~km}$ and the other around $17 \mathrm{~km}$. Both structures are separated by a small layer with higher CFC-11 VMRs. This small layer has a vertical extent of considerably less than $1 \mathrm{~km}$, which illustrates the unprecedented vertical resolution achievable with the CRISTA-NF measurements. The lower structure of low CFC-11 values is in good agreement with the upper part of the structure with high values of mPV shown in Fig. 2a. This suggests that the air masses consist to a large part of air originating from the polar vortex. In contrast to this, the upper structure is located in a region with moderate values of $\mathrm{mPV}$, indicating a different origin. The horizontal distribution of PV (not shown here) shows that the two structures are vertical cuts through filamentary structures. The two areas at the end of the flight showing low CFC-11 VMRs are hereafter denoted as lower and upper filament.

The cross-sections of $\mathrm{ClONO}_{2}$ and $\mathrm{O}_{3}$ (Fig. $3 \mathrm{~b}$ and c) confirm these observations. The area identified as polar vortex shows very high $\mathrm{ClONO}_{2}$ VMRs up to $1.5 \mathrm{ppbv}$. These high values are caused by the subsidence of the air masses inside the polar vortex and the chlorine deactivation after the cold phase of the vortex and the presence of polar stratospheric clouds. The main process after the onset of chlorine deactivation in the Arctic is the formation of $\mathrm{ClONO}_{2}$ via the reaction of $\mathrm{ClO}$ and $\mathrm{NO}_{2}$, whereas the formation of $\mathrm{HCl}$ (via the reaction of $\mathrm{Cl}$ and $\mathrm{CH}_{4}$ ) is slowed down because of the typically small $\mathrm{Cl} / \mathrm{ClO}$ fraction in the Arctic (e.g. Douglass et al., 1995; Santee et al., 2008). Thus, very high $\mathrm{ClONO}_{2}$ VMRs, larger than at the beginning of the winter, are expected in early March inside the vortex and vortex air masses.

The ozone VMRs inside the polar vortex are lower or equal to the volume mixing ratios outside the vortex at comparable altitudes. These VMRs are a consequence of the ozone depletion inside the vortex. If no chemical ozone depletion had occurred, the ozone VMRs inside the vortex would be larger than outside the vortex because of the subsidence of air masses inside the vortex and the related downward transport of ozone-rich air masses from higher altitudes. This argument is valid below $\approx 475 \mathrm{~K}$ (flight altitude inside the vortex $\approx 450 \mathrm{~K})$.

The ozone and $\mathrm{ClONO}_{2}$ VMRs inside the two filaments at the end of the flight show large differences, although the $\mathrm{CFC}-11$ volume mixing ratios are very similar. The $\mathrm{O}_{3}$ VMRs in the upper filament are significantly higher and the $\mathrm{ClONO}_{2}$ VMRs significantly lower than the corresponding values in the lower filament. Therefore, only the air masses

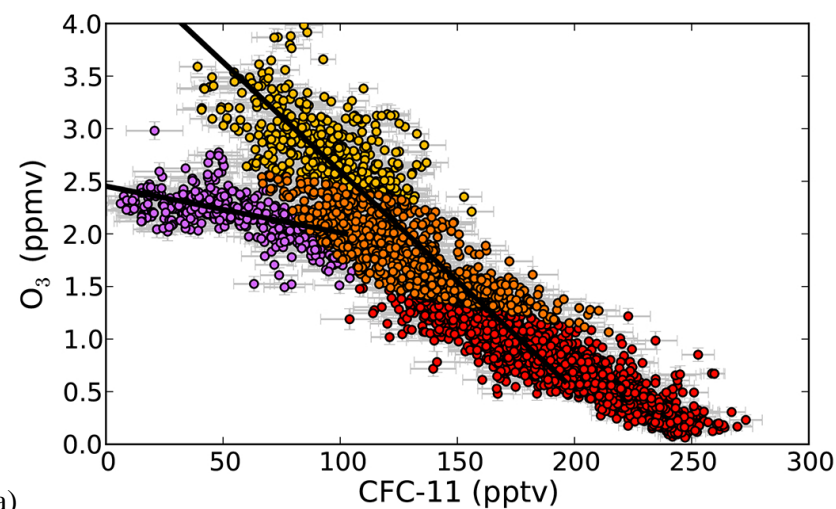

(a)

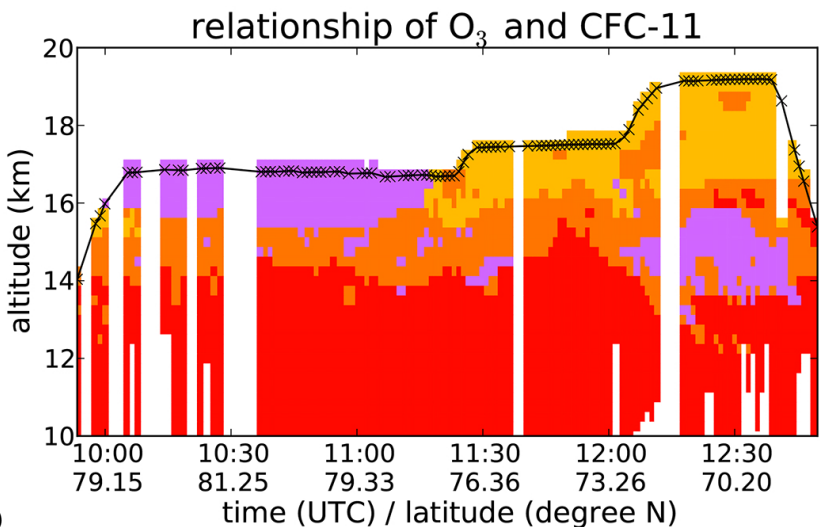

Fig. 4. Relationship between $\mathrm{CFC}-11$ and $\mathrm{O}_{3}$ for retrieved trace gas VMRs. Panel (a) shows a scatter plot for all measured air parcels with two black lines corresponding to typical correlations for vortex and non-vortex air. Purple parcels are thus categorised as vortex air, while yellow and red parcels consist of non-vortex air. Orange parcels cannot be clearly distinguished according to this criterion. The error bars show the precision of the measurements. Panel (b) shows the geo-spatial distribution of the same air parcels using the same colours.

inside the lower filament show the influence of chlorine deactivation and ozone depletion. This confirms that only the lower filament contains air with a large fraction of vortex air.

In order to analyse these differences of the air masses inside both filaments in more detail, $\mathrm{O}_{3}-\mathrm{CFC}-11$ tracer-tracer correlations are used here. Figure $4 \mathrm{a}$ shows a scatter plot of the retrieved VMRs for CFC-11 and $\mathrm{O}_{3}$. Two characteristic correlations are visible that represent the different relationships between these trace gases for the different regions inside and outside the vortex (e.g. Müller et al., 2005; Plumb, 2007). The two correlation lines were determined for air parcels stemming obviously from the vortex branch (CFC11 VMRs of less than 70 pptv and $\mathrm{O}_{3}$ VMRs of less than $2.7 \mathrm{ppmv})$ and parcels stemming from outside the vortex $\left(\mathrm{O}_{3}\right.$ VMRs above $2.7 \mathrm{ppmv}$ or between 0.6 and $1.6 \mathrm{ppmv})$. For simplicity's sake linear correlations are used here. For certain parcels, no definite judgement can be made, as the correlation lines meet. The assignment of parcels is transferred from tracer-tracer space to geo-spatial space and is shown 
in Fig. 4b. The lower part of the polar vortex can be identified above $15.5 \mathrm{~km}$ in the first half of the flight. Also the classification of the lower and upper filament at 12:30 UTC is asserted, as only the lower filament has the chemical relationship between $\mathrm{CFC}-11$ and $\mathrm{O}_{3}$ typical of vortex air. In addition, at least one further small filament of vortex air is suggested by the chemical relationship at 11:30 UTC and $14 \mathrm{~km}$ altitude.

\section{Comparison of CRISTA-NF and CLaMS and analysis of the air mass origin}

This section proceeds with the comparison of the CRISTANF results and simulations by CLaMS to assess the performance of the model. Additionally, the concept of passive tracers, which is capable of identifying different air mass origins, is analysed by means of the CRISTA-NF results.

All CLaMS results are interpolated in time and space onto the CRISTA-NF retrieval grid. Thereby, two CLaMS model outputs at two different times, one before the flight start and the other after the flight end, are used. A vertical convolution of the CLaMS results with the averaging kernels of the retrieval results is omitted, since the vertical resolution of the CRISTA-NF and CLaMS results is very similar.

\subsection{Comparison of trace gases}

Figure 5a displays the cross-section of the CLaMS result for CFC-11. The distribution of CFC-11 is mainly determined by advection and mixing processes and therefore well suited to assess the performance of CLaMS in terms of these processes.

All main structures observed by CRISTA-NF are well reproduced by CLaMS. The part of the polar vortex and the two observed filaments with low CFC-11 VMRs are visible in the CLaMS result, albeit the horizontal location and extent of the structures is slightly different. Even the thin layer with higher CFC-11 VMRs between the two filaments and the air masses with enhanced VMRs immediately below flight altitude at the end of the flight are captured by CLaMS. Nevertheless, some small differences can be seen. For example, the small structures in the vortex edge region around 11:20 UTC between $17 \mathrm{~km}$ and $14 \mathrm{~km}$ are missing in the model result. But according to the different horizontal resolution of both results (CRISTA-NF $\approx 15 \mathrm{~km}$; CLaMS $\approx 70 \mathrm{~km}$ ), these small differences are at least partly caused by the lower resolution of CLaMS. However, the CFC-11 cross-sections are quantitatively and qualitatively in very good agreement, which indicates the good performance of CLaMS in terms of advection and mixing.

The cross-section of $\mathrm{ClONO}_{2}$ is shown in Fig. 5b. The CLaMS result is in good agreement with the CRISTA-NF retrieval result, although some differences inside the vortex and the vortex filament are visible. Inside the lower filament

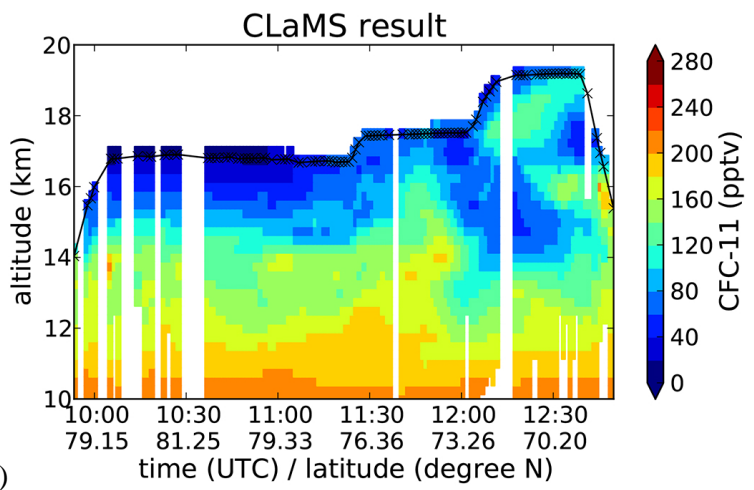

(a)

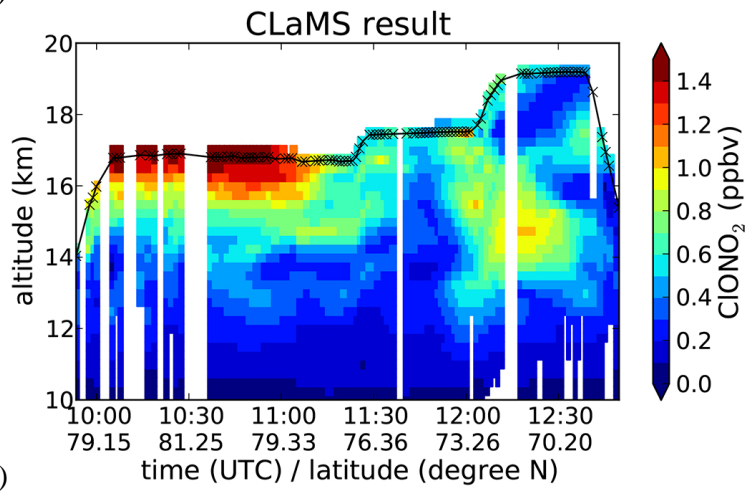

(b)

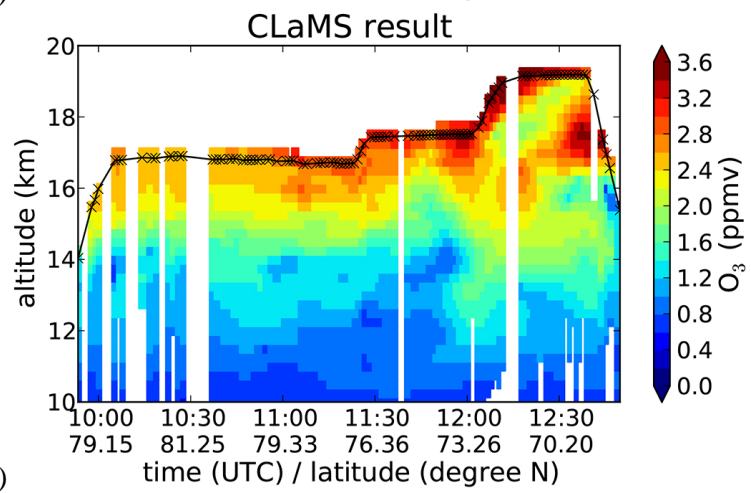

Fig. 5. CLaMS results for CFC-11, $\mathrm{ClONO}_{2}$, and $\mathrm{O}_{3}$ for $\mathrm{RECON}$ CILE flight 11 (2 March 2010). For details see caption of Fig. 3.

at the end of the flight the $\mathrm{ClONO}_{2}$ VMRs of the CLaMS result are lower compared to the retrieval result. Furthermore, the vertical extent of the area with very high volume mixing ratios below flight altitude at the beginning of the flight is smaller in the CLaMS result. These differences point to small deficiencies in the chlorine activation and deactivation simulated by CLaMS.

Figure 5c shows the CLaMS result for ozone. The only obvious difference between the CLaMS result and the CRISTANF result is visible in the polar vortex, where the CLaMS result exhibits higher ozone VMRs. A maximum discrepancy of up to 0.4 ppmv can be seen. This difference is most likely a consequence of an underestimation of ozone depletion by CLaMS that may be related to deficiencies in the simulated chlorine activation (see above). Comparisons between 
CLaMS results for $\mathrm{HCl}$ (not measured by CRISTA-NF) with satellite measurements by Aura-MLS and ACE-FTS in the time period from the beginning of December to the end of March (not shown in this paper) confirm the assumption. Inside the polar vortex in January the HCl VMRs of CLaMS are significantly higher than those of the satellite measurements in the analysed altitude range from 400 to $550 \mathrm{~K}$. This indicates an underestimation of the chlorine activation from the reservoir species $\mathrm{HCl}$, which leads to an underestimation of ozone depletion. Since the chlorine deactivation in the Arctic is mainly driven by the formation of $\mathrm{ClONO}_{2}$, the observed differences for $\mathrm{ClONO}_{2}$ are most likely a consequence of this underestimation of chlorine activation as well.

In summary, CLaMS is well suited to simulate the observed dynamical situation, especially for the tracer CFC-11. In the following, we therefore use the observed CFC-11 field together with the passive tracer concept of CLaMS to gain further insight into the origin of the observed air masses.

\subsection{Air mass origin}

In Sect. 5 we have shown that CRISTA-NF observed a part of the polar vortex and a vortex filament during the RECONCILE flight 11 on 2 March 2010. Thus, this data set is suitable to analyse the capability of the CLaMS passive tracers to identify different air masses. The history of the polar vortex during the whole winter is essential for the interpretation of the results for the passive tracers and the comparisons with the observations. Thus, the two split events during the sudden stratospheric warmings in December and February have to be taken into account (see Sect. 4). The CRISTA-NF observations were made in a part of the rejoining vortex at the beginning of March. In order to get a better comparison with these observations and to analyse the evolution of the vortex during the aircraft campaign (17 January to 10 March 2010) we use the passive tracers initialised on 15 January 2010 and, therefore, exclude the vortex split in December from the analysis. Thus, all air masses inside the vortex on 15 January, including those air masses transported into the vortex during December, were initialised as vortex air masses.

The cross-section of the CLaMS vortex tracer is shown in Fig. 6 a for the time of observation. The vortex fraction inside the polar vortex partly exceeds 0.9 at the highest altitudes. Thus, the part of the polar vortex observed by CRISTA-NF on 2 March is comparable to the vortex on 15 January in terms of the composition, as indicated by the very high values of the vortex fraction. The vortex fraction in the core of the vortex filament located at the end of the flight at $14 \mathrm{~km}$ is larger than 0.7. In the region of the upper filament (around $17 \mathrm{~km}$ at the end of the flight) the vortex tracer is very low, indicating only a minor fraction of vortex air masses in this region. These results are in very good agreement with the observations by CRISTA-NF, which showed that the lower filament with low CFC-11 VMRs is a vortex filament and the air masses in the upper filament are of different origin

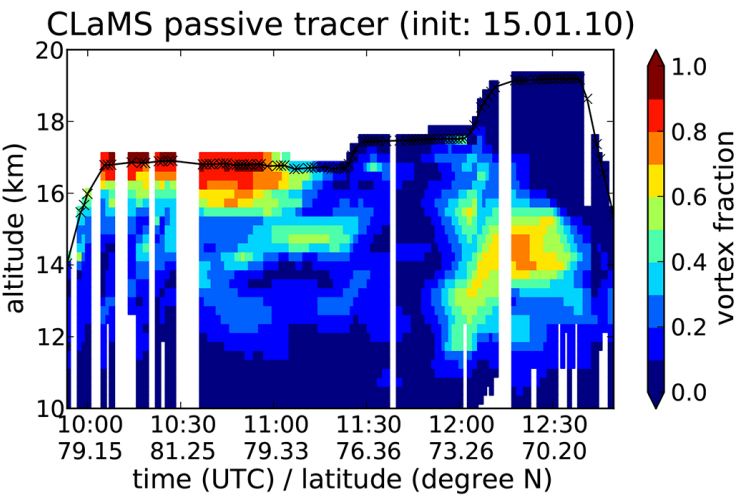

(a)

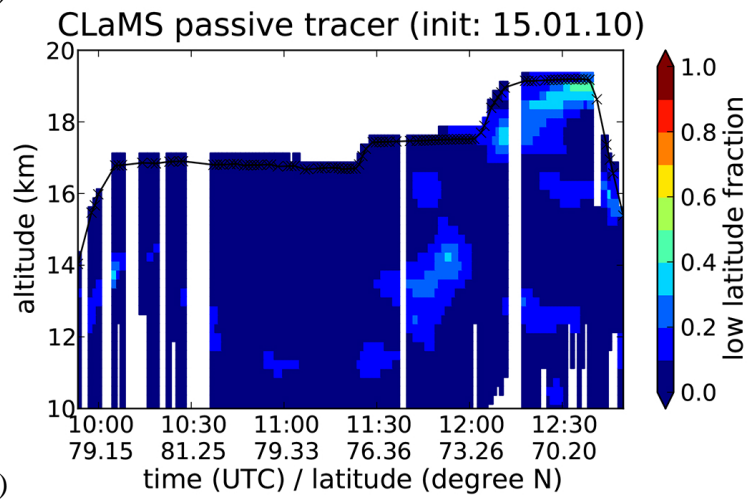

(b)

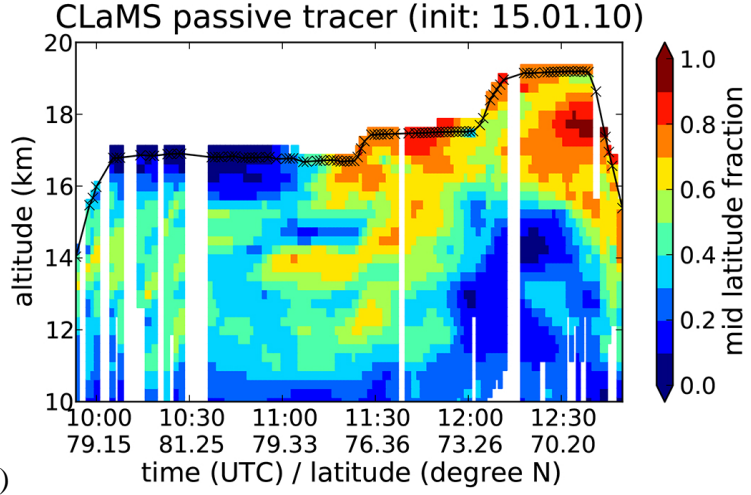

Fig. 6. Cross-sections of the CLaMS vortex tracer, low-latitude tracer, and mid-latitude tracer with initialisation on 15 January. For details see caption of Fig. 3 .

by means of $\mathrm{O}_{3}-\mathrm{CFC}-11$ tracer-tracer correlations (compare Sect. 5). Hence, by using the initialisation date of 15 January, the CLaMS vortex tracer provides a picture which is consistent with the air mass classification obtained from the CRISTA-NF measurements (compare Fig. 4b). This suggests that other passive tracers can be used to analyse the whole situation during the flight in more detail.

Figure $6 \mathrm{~b}$ displays the cross-section for the low-latitude tracer. At the end of the flight in the region between flight altitude and $15 \mathrm{~km}$ the low-latitude tracer reaches values up to 0.5 . The areas of high low-latitude fraction correspond to the areas showing higher CFC-11 VMRs immediately below flight altitude and between the two filaments with low 


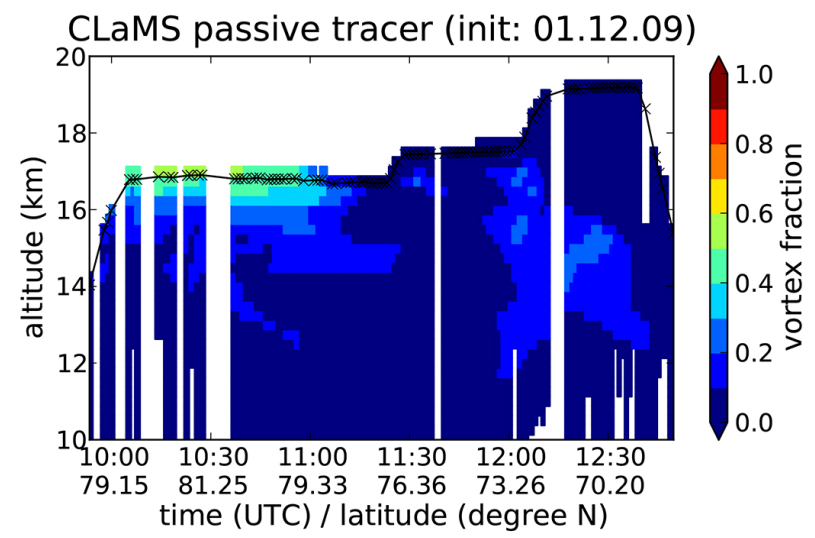

Fig. 7. Cross-section of the CLaMS vortex tracer with initialisation on 1 December. For details see caption of Fig. 3.

CFC-11 VMRs (compare Figs. 3a and 5a). Thus, this explains the observation of the upper filament with low CFC-11 VMRs. The filament is only visible because the surrounding air masses consist to a noticeable amount of low-latitude air masses and the CFC-11 VMRs are therefore significantly higher. This leads to the large contrast between the air masses inside the upper filament and the surrounding air masses. The mid-latitude tracer displayed in Fig. 6c shows that the air masses inside the upper filament consist to the largest part of mid-latitude air. Therefore, the air mass composition of the upper filament is very similar to large parts of the air masses observed outside the vortex between flight altitude and $15 \mathrm{~km}$. Hence, the low-latitude air masses correspond to the real filament at the end of the flight, which surrounds air masses of mostly mid-latitude origin.

In addition, several other structures influenced by lowlatitude air masses are visible in Fig. 6b, like the area below $15 \mathrm{~km}$ in the middle of the flight (11:30-12:00 UTC). The low-latitude fraction reaches values up to 0.3 in this area. Corresponding to this low-latitude influence the CFC11 VMRs in this area are comparably high, whereas the $\mathrm{ClONO}_{2}$ and $\mathrm{O}_{3}$ VMRs are comparably low (compare Figs. 3 and 5). But the comparison between the retrieval and the CLaMS results shows that the observed structure in the middle of the flight between 15 and $11 \mathrm{~km}$ is not as pronounced in the simulation results as in the retrieval results. The simulated VMRs do not reach the same maximum values for CFC-11 and minimum values for $\mathrm{ClONO}_{2}$ and ozone. This suggests that the fraction of low-latitude air masses in this area might be slightly underestimated by the model.

In order to obtain more insight into the split event in December and the associated in-mixing of air masses into the vortex, we use the passive tracer experiment where the passive tracers were initialised before the vortex split on 1 December 2009. We chose this initialisation date to get a robust initialisation of the passive tracers before the split and mixing event in December, since the polar vortex was stable and co-

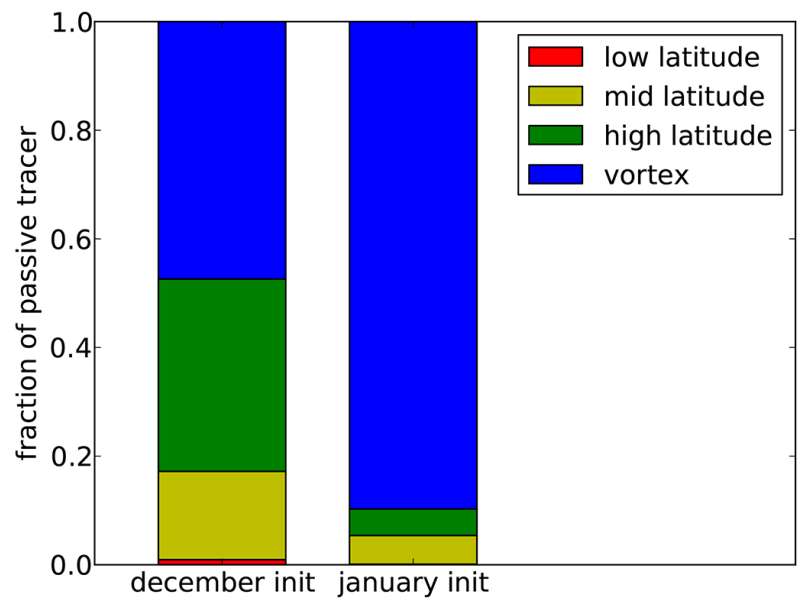

Fig. 8. Fraction of passive tracers for low-latitude, mid-latitude, high-latitude and vortex air masses inside the polar vortex (10:05 to 11:00 UTC) around flight altitude $(\approx 450 \mathrm{~K}$ potential temperature $)$ for December and January initialisations.

herent on 1 December. The CLaMS vortex tracer initialised on 1 December is displayed in Fig. 7 at the time of observation. Inside the polar vortex the tracer only reaches maximum values of about 0.5 at flight altitude, which indicates that the observed air masses contain $50 \%$ vortex air masses. Furthermore, the vortex filament at the end of the flight can hardly be seen. Thus, there is a large difference between the vortex tracers of the two initialisations. The lower vortex fraction inside the vortex observed for the December initialisation is caused by in-mixing of air masses in mid-December. If no air masses had mixed into the vortex, the vortex tracers of both initialisations would be the same. As a consequence of this in-mixing of air masses in December, the composition of the vortex changed and, therefore, the vortex tracers of the two initialisations represent vortex air masses of different composition. A comparison between the passive tracers of both initialisations can now be used to gain information on the amount of air masses mixed into the vortex. The difference between the passive tracers of both initialisations inside the polar vortex between 10:05 and 11:00 UTC (excluding the ascent and the vortex edge region) around flight altitude $(\approx 450 \mathrm{~K}$ potential temperature $)$ is illustrated in Fig. 8 . The boxes show the average values of the passive tracers inside the polar vortex for both initialisation dates. Obviously, the polar vortex was very stable with respect to in-mixing of air masses after 15 January, which is illustrated by the very high average value of the vortex fraction (blue) for the January initialisation of $\approx 0.90$. Hence, only very few air masses were mixed into the vortex after 15 January. Thus, the large reduction of the vortex fraction of the December initialisation can be almost fully attributed to the in-mixing of air masses into the vortex during December. The difference between the vortex fractions of both initialisation dates $(\approx 0.47$ for December initialisation to $\approx 0.90$ for January) gives a reasonable 
estimate of the amount of air masses mixed into the vortex in December. These air masses account for about $45 \%$ of the total air masses inside the re-established polar vortex at the end of December.

Since the sum of all passive tracers in one air parcel is always 1 , the positive change in the vortex fraction has to be compensated by negative changes in the remaining tracers (high-latitude, mid-latitude, low-latitude). These changes are visible in Fig. 8 by a reduction of the high- and mid-latitude fractions from December to January initialisation. These reductions in relation to the change in the vortex fraction and the ratio of the average values of the high- and mid-latitude fractions for the December initialisation (about $70: 30$ ) give an estimate of the contributions of both air mass types to the air masses mixed into the vortex. Hence, high-latitude air masses contributed most to the air masses mixed into the vortex (about $70 \%$ ) and mid-latitude air masses were the second important contributor (about $30 \%$ ). The contribution of low-latitude air masses is negligible.

\section{Summary and conclusions}

We presented high-resolution cross-sections of CFC-11, $\mathrm{O}_{3}$, and $\mathrm{ClONO}_{2}$ derived from the CRISTA-NF measurements in the polar UTLS on 2 March 2010. The observations included vortex air masses, indicating the bottom edge of the polar vortex at $\approx 15.5 \mathrm{~km}$. Two filaments with very low CFC- 11 VMRs were observed, which could be analysed in terms of transport and mixing. By means of $\mathrm{O}_{3}-\mathrm{CFC}-11$ tracer-tracer correlations one of these filaments could clearly be identified as a vortex filament, whereas the other filament had the same characteristics as air outside the vortex. Large parts of the trace gas fields and small-scale structures observed by CRISTA-NF can be quantitatively reproduced by CLaMS simulations. This confirms the excellent representation of advection and mixing in this model. Some small differences between the observations and simulations concern the ozone chemistry inside the polar vortex. Simulated ozone VMRs inside the vortex suggest a somewhat smaller ozone loss than observed values (up to $0.4 \mathrm{ppmv}$ ). Comparisons with satellite observations suggest that this deviation is mainly caused by an underestimation of chlorine activation from the reservoir species $\mathrm{HCl}$ in the model.

Furthermore, we analysed the composition of origins of the observed air masses based on a passive tracer concept. Each of these passive tracers represents another air mass origin (e.g. vortex, low latitudes). An initialisation of the passive tracers on 15 January 2010 provides a picture that is consistent with the CRISTA-NF observations and even provides information on the origin of air masses that goes beyond the observation. Based on this scheme, we showed that several filaments had tropical origin and were transported towards the pole. A distinctive feature of the Arctic winter 2009/2010 was a sudden stratospheric warming in early December that led to a vortex split. Thus, a passive tracer experiment, initialised on 1 December 2009, was used to gain information on the effects of this split event in December on the composition of the vortex. The comparison of the results of both passive tracer experiments (initialised on 1 December 2009 and 15 January 2010) illustrated that a large amount (about $45 \%$ ) of air masses from outside the vortex were mixed into the vortex. As a consequence, the re-established vortex at the end of December 2009 contained air masses originally originating from mid- and high latitudes.

Acknowledgements. The RECONCILE project is funded under the European Commission Seventh Framework Programme (FP7) under the Grant number RECONCILE-226365-FP7-ENV-2008-1. We thank the RECONCILE Coordination and flight planning teams, MDB and Enviscope for the successful implementation of and support during the Arctic field campaign. The ECMWF data are provided by the European Center for Medium range Weather Forecast. We further thank W. Woiwode and H. Oelhaf from the Karlsruhe Institute of Technology (KIT) for providing the MIPAS-STR AHRS attitude measurements. Furthermore, we thank the AURA-MLS team, the MIPAS-ENV team, and the ACE-FTS team for providing data used for the initialisation of CLaMS.

Edited by: F. Khosrawi

\section{References}

Bernath, P. F., McElroy, C. T., Abrams, M. C., Boone, C. D., Butler, M., Camy-Peyret, C., Carleer, M., Clerbaux, C., Coheur, P.F., Colin, R., DeCola, P., DeMaziére, M., Drummond, J. R., Dufour, D., Evans, W. F. J., Fast, H., Fussen, D., Gilbert, K., Jennings, D. E., Llewellyn, E. J., Lowe, R. P., Mahieu, E., McConnell, J. C., McHugh, M., McLeod, S. D., Michaud, R., Midwinter, C., Nassar, R., Nichitiu, F., Nowlan, C., Rinsland, C. P., Rochon, Y. J., Rowlands, N., Semeniuk, K., Simon, P., Skelton, R., Sloan, J. J., Soucy, M.-A., Strong, K., Tremblay, P., Turnbull, D., Walker, K. A., Walkty, I., Wardle, D. A., Wehrle, V., Zander, R., and Zou, J.: Atmospheric Chemistry Experiment (ACE): mission overview, Geophys. Res. Lett., 32, L15S01, doi:10.1029/2005GL022386, 2005.

Birner, T., Sankey, D, and Shepherd, T. G.: The tropopause inversion layer in models and analyses, Geophys. Res. Lett., 33, L14804, doi:10.1029/2006GL026549, 2006.

Dörnbrack, A., Pitts, M. C., Poole, L. R., Orsolini, Y. J., Nishii, K., and Nakamura, H.: The 2009-2010 Arctic stratospheric winter general evolution, mountain waves and predictability of an operational weather forecast model, Atmos. Chem. Phys., 12, 36593675, doi:10.5194/acp-12-3659-2012, 2012.

Douglass, A. R., Schoeberl, M. R., Stolarski, R. S., Waters III, J. J. M. R., Roche, A. E., and Massie, S. T.: Interhemispheric differences in springtime production of $\mathrm{HCl}$ and $\mathrm{ClONO}_{2}$ in the polar vortices, J. Geophys. Res., 100, 13967-13978, 1995.

Fastie, W.: Ebert Spectrometer Reflections, Phys. Today, 4, 37-43, 1991.

Fischer, H., Birk, M., Blom, C., Carli, B., Carlotti, M., von Clarmann, T., Delbouille, L., Dudhia, A., Ehhalt, D., Endemann, M., 
Flaud, J. M., Gessner, R., Kleinert, A., Koopman, R., Langen, J., López-Puertas, M., Mosner, P., Nett, H., Oelhaf, H., Perron, G., Remedios, J., Ridolfi, M., Stiller, G., and Zander, R.: MIPAS: an instrument for atmospheric and climate research, Atmos. Chem. Phys., 8, 2151-2188, doi:10.5194/acp-8-2151-2008, 2008.

Grooß, J.-U., Günther, G., Müller, R., Konopka, P., Bausch, S., Schlager, H., Voigt, C., Volk, C. M., and Toon, G. C.: Simulation of denitrification and ozone loss for the Arctic winter 2002/2003, Atmos. Chem. Phys., 5, 1437-1448, doi:10.5194/acp-5-14372005, 2005.

Grooß, J.-U., Engel, I., Borrmann, S., Frey, W., Günther, G., Hoyle, C. R., Kivi, R., Luo, B. P., Molleker, S., Peter, T., Pitts, M. C., Schlager, H., Stiller, G., Vömel, H., Walker, K. A., and Müller, R.: NAT nucleation and denitrification in the Arctic stratosphere, Atmos. Chem. Phys. Discuss., 13, 22107-22150, doi:10.5194/acpd-13-22107-2013, 2013.

Grossmann, K. U., Offermann, D., Gusev, O., Oberheide, J., Riese, M., and Spang, R.: The CRISTA-2 mission, J. Geophys. Res., 107, 8173, doi:10.1029/2001JD000667, 2002.

Günther, G., Müller, R., von Hobe, M., Stroh, F., Konopka, P., and Volk, C. M.: Quantification of transport across the boundary of the lower stratospheric vortex during Arctic winter 2002/2003, Atmos. Chem. Phys., 8, 3655-3670, doi:10.5194/acp-8-36552008, 2008.

Hoffmann, L. and Alexander, M. J.: Retrieval of stratospheric temperatures from Atmospheric Infrared Sounder radiance measurements for gravity wave studies, J. Geophys. Res., 114, D07105, doi:10.1029/2008JD011241, 2009.

Hoffmann, L., Kaufmann, M., Spang, R., Müller, R., Remedios, J. J., Moore, D. P., Volk, C. M., von Clarmann, T., and Riese, M.: Envisat MIPAS measurements of CFC-11: retrieval, validation, and climatology, Atmos. Chem. Phys., 8, 3671-3688, doi:10.5194/acp-8-3671-2008, 2008.

Hoffmann, L., Weigel, K., Spang, R., Schroeder, S., Arndt, K., Lehmann, C., Kaufmann, M., Ern, M., Preusse, P., Stroh, F., and Riese, M.: CRISTA-NF measurements of water vapor during the SCOUT-O $_{3}$ Tropical Aircraft Campaign, Adv. Space Res., 43, 74-81, doi:10.1016/j.asr.2008.03.018, 2009.

Hoor, P., Fischer, H., Lange, L., Lelieveld, J., and Brunner, D.: Seasonal variations of a mixing layer in the lowermost stratosphere as identified by the $\mathrm{CO}-\mathrm{O}_{3}$ correlation from in situ measurements, J. Geophys. Res., 107, 4044, doi:10.1029/2000JD000289, 2002.

IPCC: Climate Change 2007: The Physical Science Basis, Contributions of Working Group I to the Fourth Assessment Report of the Intergovernmental Panel on Climate Change, edited by: Solomon, S., Qin, D., Manning, M., Chen, Z., Marquis, M., Averyt, K. B., Tignor, M., and Miller, H. L., Cambridge University Press, Cambridge, United Kingdom and New York, NY, USA, 2007

Konopka, P., Steinhorst, H.-M., Grooß, J.-U., Günther, G., Müller, R., Elkins, J. W., Jost, H.-J., Richard, E., Schmidt, U., Toon, G., and McKenna, D. S.: Mixing and ozone loss in the 1999-2000 Arctic vortex: simulations with the three-dimensional Chemical Lagrangian Model of the Stratosphere (CLaMS), J. Geophys. Res., 109, D02315, doi:10.1029/2003JD003792, 2004.

Konopka, P., Günther, G., Müller, R., dos Santos, F. H. S., Schiller, C., Ravegnani, F., Ulanovsky, A., Schlager, H.,
Volk, C. M., Viciani, S., Pan, L. L., McKenna, D.-S., and Riese, M.: Contribution of mixing to upward transport across the tropical tropopause layer (TTL), Atmos. Chem. Phys., 7, 32853308, doi:10.5194/acp-7-3285-2007, 2007.

Kullmann, A., Riese, M., Olschewski, F., Stroh, F., and Grossmann, K. U.: Cryogenic infrared spectrometers and telescopes for the atmosphere - new Frontiers, Proc. SPIE, 5570, 423-432, 2004.

Lait, L. R.: An alternative form for potential vorticity, J. Atmos. Sci., 51, 1754-1759, 1994.

McKenna, D. S., Grooß, J.-U., Günther, G., Konopka, P., Müller, R., Carver, G., and Sasano, Y.: A new Chemical Lagrangian Model of the Stratosphere (CLaMS) 2. formulation of chemistry scheme and initialization, J. Geophys. Res., 107, 4256, doi:10.1029/2000JD000113, 2002a.

McKenna, D. S., Konopka, P., Grooß, J.-U., Günther, G., Müller, R., Spang, R., Offermann, D., and Orsolini, Y.: A new Chemical Lagrangian Model of the Stratosphere (CLaMS) 1. formulation of advection and mixing, J. Geophys. Res., 107, 4309, doi:10.1029/2000JD000114, 2002b.

Müller, R. and Günther, G.: A generalized form of Lait's Modified Potential Vorticity, J. Atmos. Sci., 60, 2229-2237, 2003.

Müller, R., Tilmes, S., Konopka, P., Grooß, J.-U., and Jost, H.J.: Impact of mixing and chemical change on ozone-tracer relations in the polar vortex, Atmos. Chem. Phys., 5, 3139-3151, doi:10.5194/acp-5-3139-2005, 2005.

Nash, E. R., Newman, P. A., Rosenfield, J. E., and Schoeberl, M. R.: An objective determination of the polar vortex using Ertel's potential vorticity, J. Geophys. Res., 101, 9471-9478, 1996.

Offermann, D., Grossmann, K.-U., Barthol, P., Knieling, P., Riese, M., and Trant, R.: Cryogenic Infrared Spectrometers and Telescopes for the Atmosphere (CRISTA) experiment and middle atmosphere variability, J. Geophys. Res., 104, 16311-16325, doi:10.1029/1998JD100047, 1999.

Plumb, R. A.: Tracer interrelationships in the stratosphere, Rev. Geophys., 45, RG4005, doi:10.1029/2005RG000179, 2007.

Riese, M., Tie, X., Brasseur, G., and Offermann, D.: Threedimensional simulation of stratospheric trace gas distributions measured by CRISTA, J. Geophys. Res., 104, 16419-16435, doi:10.1029/1999JD900178, 1999.

Riese, M., Manney, G. L., Oberheide, J., Tie, X., Spang, R., and Küll, V.: Stratospheric transport by planetary wave mixing as observed during CRISTA-2, J. Geophys. Res., 107, 8179, doi:10.1029/2001JD000629, 2002.

Riese, M., Ploeger, F., Rap, A., Vogel, B., Konopka, P., Dameris, M., and Forster, P.: Impact of uncertainties in atmospheric mixing on simulated UTLS composition and related radiative effects, J. Geophys. Res., 117, D16305, doi:10.1029/2012JD017751, 2012.

Santee, M., MacKenzie, I., Manney, G., Chipperfield, M. Bernath, P., Walker, K., Boone, C., Froidevaux, L., Livesey, N., and Waters, J.: A study of stratospheric chlorine partitioning based on new satellite measurements and modeling, J. Geophys. Res., 113, D12307, doi:10.1029/2007JD009057, 2008.

Schroeder, S., Kullman, A., Preusse, P., Stroh, F., Weigel, K., Ern, M., Knieling, P., Olschewski, F., Spang, R., and Riese, M.: Radiance calibration of CRISTA-NF, Adv. Space Res., 43, 19101917, doi:10.1016/j.asr.2009.03.009, 2009.

Spang, R., Hoffmann, L., Kullmann, A., Olschewski, F., Preusse, P., Knieling, P., Schroeder, S., Stroh, F., Weigel, K., and Riese, M.: 
High resolution limb observations of clouds by the CRISTA-NF experiment during the SCOUT-O3 tropical aircraft campaign, Adv. Space Res., 42, 1765-1775, doi:10.1016/j.asr.2007.09.036, 2008.

Ungermann, J.: Improving retrieval quality for airborne limb sounders by horizontal regularisation, Atmos. Meas. Tech., 6, 15-32, doi:10.5194/amt-6-15-2013, 2013.

Ungermann, J., Hoffmann, L., Preusse, P., Kaufmann, M., and Riese, M.: Tomographic retrieval approach for mesoscale gravity wave observations by the PREMIER Infrared Limb-Sounder, Atmos. Meas. Tech., 3, 339-354, doi:10.5194/amt-3-339-2010, 2010 .

Ungermann, J., Kalicinsky, C., Olschewski, F., Knieling, P., Hoffmann, L., Blank, J., Woiwode, W., Oelhaf, H., Hösen, E., Volk, C. M., Ulanovsky, A., Ravegnani, F., Weigel, K., Stroh, F., and Riese, M.: CRISTA-NF measurements with unprecedented vertical resolution during the RECONCILE aircraft campaign, Atmos. Meas. Tech., 5, 1173-1191, doi:10.5194/amt-5-11732012, 2012.

Ungermann, J., Pan, L. L., Kalicinsky, C., Olschewski, F., Knieling, P., Blank, J., Weigel, K., Guggenmoser, T., Stroh, F., Hoffmann, L., and Riese, M.: Filamentary structure in chemical tracer distributions near the subtropical jet following a wave breaking event, Atmos. Chem. Phys. Discuss., 13, 5039-5089, doi:10.5194/acpd-13-5039-2013, 2013.

von Hobe, M., Bekki, S., Borrmann, S., Cairo, F., D’Amato, F., Di Donfrancesco, G., Dörnbrack, A., Ebersoldt, A., Ebert, M., Emde, C., Engel, I., Ern, M., Frey, W., Genco, S., Griessbach, S., Grooß, J.-U., Gulde, T., Günther, G., Hösen, E., Hoffmann, L., Homonnai, V., Hoyle, C. R., Isaksen, I. S. A., Jackson, D. R., Jánosi, I. M., Jones, R. L., Kandler, K., Kalicinsky, C., Keil, A., Khaykin, S. M., Khosrawi, F., Kivi, R., Kuttippurath, J., Laube, J. C., Lefèvre, F., Lehmann, R., Ludmann, S., Luo, B. P., Marchand, M., Meyer, J., Mitev, V., Molleker, S., Müller, R., Oelhaf, H., Olschewski, F., Orsolini, Y., Peter, T., Pfeilsticker, K., Piesch, C., Pitts, M. C., Poole, L. R., Pope, F. D., Ravegnani, F., Rex, M., Riese, M., Röckmann, T., Rognerud, B., Roiger, A., Rolf, C., Santee, M. L., Scheibe, M., Schiller, C., Schlager, H., Siciliani de Cumis, M., Sitnikov, N., Søvde, O. A., Spang, R., Spelten, N., Stordal, F., Sumin'ska-Ebersoldt, O., Ulanovski, A., Ungermann, J., Viciani, S., Volk, C. M., vom Scheidt, M., von der Gathen, P., Walker, K., Wegner, T., Weigel, R., Weinbruch, S., Wetzel, G., Wienhold, F. G., Wohltmann, I., Woiwode, W., Young, I. A. K., Yushkov, V., Zobrist, B., and Stroh, F.: Reconciliation of essential process parameters for an enhanced predictability of Arctic stratospheric ozone loss and its climate interactions (RECONCILE): activities and results, Atmos. Chem. Phys., 13, 92339268, doi:10.5194/acp-13-9233-2013, 2013.
Waters, J., Froidevaux, L., Harwood, R., Jarnot, R., Pickett, H., Read, W., Siegel, P., Cofield, R., Filipiak, M., Flower, D., Holden, J., Lau, G., Livesey, N., Manney, G., Pumphrey, H., Santee, M., Wu, D., Cuddy, D., Lay, R., Loo, M., Perun, V., Schwartz, M., Stek, P., Thurstans, R., Boyles, M., Chandra, K., Chavez, M., Chen, G.-S., Chudasama, B., Dodge, R., Fuller, R., Girard, M., Jiang, J., Jiang, Y., Knosp, B., LaBelle, R., Lam, J., Lee, K., Miller, D., Oswald, J., Patel, N., Pukala, D., Quintero, O., Scaff, D., Van Snyder, W., Tope, M., Wagner, P., and Walch, M.: The Earth Observing System Microwave Limb Sounder (EOS MLS) on the Aura Satellite, IEEE T. Geosci. Remote, 44, 1075-1092, doi:10.1109/TGRS.2006.873771, 2006.

Weigel, K., Riese, M., Hoffmann, L., Hoefer, S., Kalicinsky, C., Knieling, P., Olschewski, F., Preusse, P., Spang, R., Stroh, F., and Volk, C. M.: CRISTA-NF measurements during the AMMASCOUT-O3 aircraft campaign, Atmos. Meas. Tech., 3, 14371455, doi:10.5194/amt-3-1437-2010, 2010.

Weigel, K., Hoffmann, L., Günther, G., Khosrawi, F., Olschewski, F., Preusse, P., Spang, R., Stroh, F., and Riese, M.: A stratospheric intrusion at the subtropical jet over the Mediterranean Sea: air-borne remote sensing observations and model results, Atmos. Chem. Phys., 12, 8423-8438, doi:10.5194/acp12-8423-2012, 2012.

WMO: Scientific Assessment of Ozone Depletion: 2006, Global Ozone Research and Monitoring Project - Report No. 50, Geneva, Switzerland, 2007. 